\title{
Potential of the Use of Social Networks in Teaching a Foreign Language in Higher Educational Institutions
}

\author{
Iryna M. Zvarych \\ Kyiv National University of Trade and Economics, Ukraine \\ http:/ / orcid.org/0000-0003-0715-9551 \\ Natalia M. Lavrychenko, Nataliya H. Zaitseva, \\ Olena M. Chaika and Oksana M. Skorobahata \\ Oleksandr Dovzhenko Hlukhiv National Pedagogical University, Ukraine \\ http://orcid.org/0000-0003-0776-7362 \\ http:// orcid.org/0000-0002-0131-5368 \\ http:/ / orcid.org/0000-0002-3650-3991 \\ http://orcid.org/0000-0002-9519-587X
}

\begin{abstract}
The article justifies the need to use social networks in teaching a foreign language in higher educational institutions. The research identified the prospects of Instagram in English language classes. Besides, the author developed the algorithm to implement the function of this social network in students' foreign language learning. The diagnostic, summative, and final stages of the experiment provided for filling of questionnaires by students. The study began with a diagnostic test to establish the level of interest of students and teachers in the use of the potential of social networks. It helped reveal the urgent need to use new social networks in the process of teaching English language to students. To verify the initial level of student's communicative competence, foreign language skills of students majoring in Pedagogy and Speciality "Foreign Language," were considered. The experiment involved 40 students. An academic group of the $1^{\text {st }}$ year of the bachelor's degree was selected to test the developed fragment of the algorithm for using the capabilities of Instagram. The age of students was 18-19 years. The results of this study include a significant improvement of students' vocabulary, training for the correct usage of grammatical structures, and bridging the language barrier while communicating in English. This technology also received positive feedback from students. Moreover, the study demonstrated the opportunities self-learning by students at home.
\end{abstract}

Keywords: informational and communicative technologies; social networks; foreign communicative competency; students; teachers 


\section{Introduction}

Today, in the current context, transparency of higher educational institutions (HEIs) to external requests, as a strong foundation, is the basis of the educational system. Thus, at the present-day stage of development of the education informatisation that provides opportunities for quick information processing and creation of new qualitative information on its basis is essential in the process of realization of these principles. In its turn, it is a foundation for the intellectual activity quality improvement of (Maguth, Yamaguchi \& Elliott, 2010). Besides, in modern higher professional education, the vital principle is the concept of the accessibility of education of any degree and forms to every individual regardless of sex, social status, nationality, and physical conditions (Mills, 2009). The outlined tendencies emphasise the possibility to use social networks in the educational process in HEIs. It will help to make education accessible to everybody. It will also activate the process of assimilation of the educational information.

For the last ten years, foreign language teachers have been actively using Internet resources to immerse students in the language environment. The integration of online radio materials, foreign-language TV programs into the educational process allows for fundamentally new vectors of development of the study process of teaching foreign languages. The use of mass media information provides a more profound mastery of a foreign language, promotes the development of students' foreign language communicative competence, orients them to the development of information culture, skills of independent acquisition of knowledge. At the same time, we note that a significant disadvantage of such resources is the lack of feedback, necessary for the communicative process. I It is essential to take into account the recipient's reaction to the source message in any act of communication (oral or written) in the process of social interaction.

At the same time, social services Web 2.0, which can be used in the learning process, provide new extensive opportunities for the exchange of different information. Many educators, psychologists, and researchers today note that the current generation of young people, who grew up on technological innovations, prefer to communicate through blogs and social networks over real social interaction. According to surveys, most students find blogs convenient and useful in learning a foreign language (Gerhart, 2017). In this regard, one of the urgent tasks of the pedagogical community is to understand the educational potential of Internet resources and the development of innovative educational technologies aimed at their practical use in the educational process (Arndt, 2017; Gerhart, 2017). The study of the existing theoretical framework allowed establishing some academic aspects of the use of social networks in the study of a foreign language in the educational process of HEIs. In particular, the specifics of motivating students to learn professional English terminology while listening to international thematic blogs are specified (Gerhart, 2017). The potential of thematic communities in Facebook (Birky \& Collins, 2011) is substantiated. We do not find practical recommendations for using the capabilities of today's popular network - Instagram. Therefore, we will try to develop a fragment of the algorithm for using Instagram in the study of English. 
From the researchers' points of view on social networks on the Internet, virtual social networks are "a social structure of the Internet environment, nets of which are organizations or certain people, where ties determine interactions established." (Mills, 2011; Roblyer, McDaniel, Webb, Herman \& Witty, 2010). In current realities of the spread of available high-speed Internet, and popularity of mobile devices with Internet access, communication with the help of social networks is becoming necessary as a breath of life for us. Every fifth user aged 18 to 34 spends 6 hours and more per day on the social networks (Gilpin, 2011). According to the results of the survey, the highest number of students from domestic HEIs use Instagram.

During the last two years, the popularity of Facebook has been increasing, especially among students of HEIs (Birky \& Collins, 2011). Nevertheless, many representatives of generation $40+$ (including teachers of HEIs) are prone to regard social networks sceptically as a waste of time. Moreover, many HEI teachers keep considering a social network mostly as an "enemy"(Maguth et al., 2010). In particular, the matter is about such service as Instagram. Trying to use social networks in their work, teachers must take into account a crucial aspect: everyone is equal in social networks. People do not find "correct" patterns of creativity and thoughts known in advance (Romano, 2009). Consequently, this demonstrates certain signs of subjectivity related to the student's sign-in (or failure to sign in) in social networks.

In general, the experience of Western countries demonstrates the effective impact of social networks on the educational process. Thus, the review of the works of modern scholars found the correlation between a teacher's presence in Facebook and "the climate" in an auditorium. This study proved that there is a relationship between the level of teacher's self-disclosure through the social network with the degree of motivation of students to study particular educational material; the relationship of student assessments with the level of teacher's "disclosure" through Facebook (Handley \& Chapman, 2011; Redston \& Cunnigham, 2012). Therefore, we believe that the higher students rate the level of teacher's selfdisclosure through the network, the better their emotional state will be.

Social networks were poorly used in the educational process in the post-Soviet countries (Boyd \& Ellison, 2007). The reason is a skeptical attitude of the teaching staff to social networks (Aksenova, 2015; Klimenko, 2012). At the same time, researchers in the sphere of education believe that application of social networks is promising in terms of improving the quality of education, in particular foreign language learning (Ballance, 2012; Chen, 2013; Reinhardt \& Chen, 2013; Lin, Warschauer \& Blake, 2016). According to them, these technologies have a serious pedagogical potential that must be understood by a professional community and implemented into practical activity (Bezukladnikov, Novosyolov \& Kruze, 2014; Mozhaeva \& Feshchenko, 2010). 
In the current circumstances, the main functions of social networks in education are as follows:

- a social network as a messenger, that is, a program for quick message exchange. Given the spread of mobile devices with Internet access, this function is convenient and publicly available. It is ideal for online consultations and organization of the current teacher-student cooperation;

- a social network as a message board. It can be used for official messages and announcements of upcoming events by structural divisions of HEIs;

- a social network as a library catalogue. Numerous special groups or communities have books on various academic subjects. Full-text copies of books increasingly appear in such online libraries due to the Internet capacity increase. It allows referring to them with the observance of all rules of scientific citing;

- a social network as a substitute for paper periodicals. Almost all modern newspapers, magazines covering economic, and management topics have groups in social networks, where they announce or publish a full text of their materials (Aydin, 2014).

- scholars stress that application of social networks in foreign language learning enables achieving the following results:

- creation of a single information environment of the educational system;

- production of high-quality, transparent, and accessible portals of educational resources;

- improving qualifications of the teaching staff, their introduction to new methodologies, motivation to be creative and to develop professionally;

- the system organization of permanent consulting and information support for all participants in the educational process;

- formation of the new thinking culture of participants in the educational process, transfer from a psychological paradigm to competency-based one, an increase of information literacy (Figure 1).

- At the same time, it is possible to distinguish the usage of social networks among other types of network technologies in the practice of foreign language teaching in HEIs (Sorokovykh, Shumeyko \& Vishnevskaya, 2020):

- a familiar environment for students: an interface, means of communication and content publication are studied thoroughly by users;

- diversity of communicational forms: wiki pages, forums, polls, voting, comments, subscriptions, sending of personal messages, and others provide a wide range of opportunities for collaboration (Kabilan, Ahmad \& Abidin, 2010; Schmitt, 2008; Yavuz, 2012).

Social networks allow students to contact their teachers, ask them questions and write some comments directly during the preparation for practical classes. For example, social networks allow posting educational videos, pictures, photos, audio records, and documents. Besides, teachers post both obligatory and additional learning materials for independent students' work on their pages or specially created accounts of educational environment quite often (Hall \& Walsh, 2002; Huang \& Hung, 2013; Junco \& Cole-Avent, 2008). 


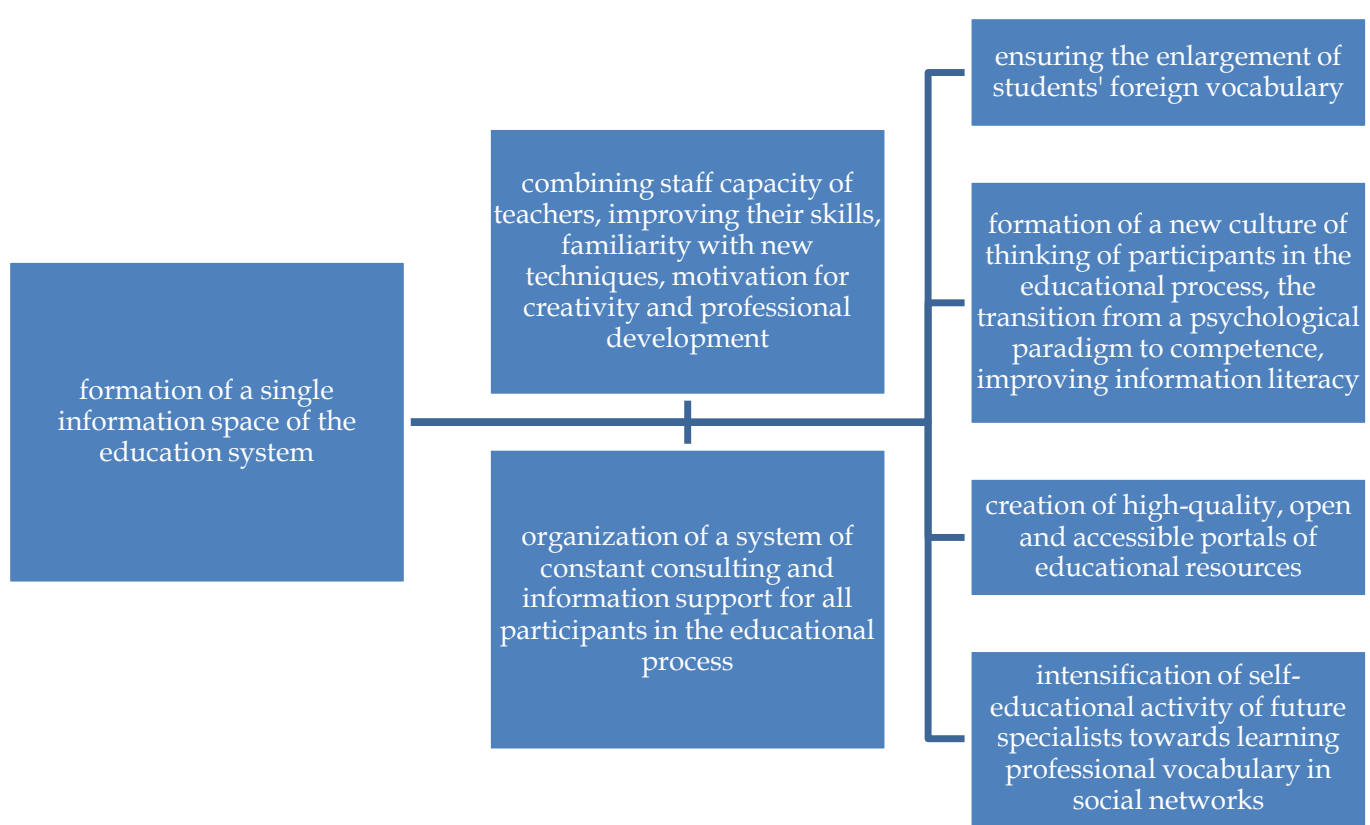

Figure 1: Theoretical scheme for the application of social networks in foreign language training

\section{Materials and Methods}

The research represents the author's idea and consisted of several stages. The first stage was to study the current level of communicative, lexical, and grammatical knowledge, skills, abilities of students. Foreign-language skills and abilities of students majoring in Pedagogical education, Speciality "Foreign Language" were measured to identify the initial level of students' communicative competence. The experiment involved forty students. A focus group was an academic group of first-year students aged 18-19 and studying for their bachelor's degree (Sorokovykh, Shumeyko \& Vishnevskaya, 2020).

Before the experiment, the state of affairs in the academic group was thoroughly analysed. The students had English classes two times a week with teaching based on the manual by Dellar and Walkley (2010). This manual was prepared jointly with National Geographic, so that it is illustrated by beautiful photos and other forms of visualization. Each level of the course consists of 100-120 hours for work in the class. The manual consists of 16 units: My First Class, Feelings, Time Off, Interests, Working Life, Going Shopping, School and Studying, Eating, Houses, Going Out, The Natural World, People I Know, Travel, Technology, Injuries and Illness, News and Events. Each unit consists of subunits: vocabulary, grammar, reading, listening, and developing conversations. It means that each topic requires the mastering of all types of speech activities.

Each unit begins with explanations of the aims for the chapter, and each unit ends with Review (generalized information on the material studied). The manual ends with assignments to work on written communication skills (Introduce Yourself, Short Emails, Stories, Making Requests, Suggesting Changes, Reports, For and Against, Review). Students can find Grammar Reference after this part, which contains short theoretical material on grammar topics and assignments for its 
mastering. The next part is Information Files containing additional materials to develop the communicative skills of students. The useful content ends with scripts for all audio records in the manual to study them thoroughly. An exciting aspect of this manual includes short insertions titled Native Speaker English in the middle of chapters. They provide information on spoken English as well as on how to use unusual and exciting phrases. For example, when we should use the word "right" (this word has several meanings). Besides, a set of educational videos accompany the course. The stated above are the advantages of the manual. However, the textbook has some disadvantages. First, the grammatical part is rather small, which is a negative side of the manual. Not all students can cope with such a format due to a lack of fundamental knowledge obtained at schools or other places. It most likely explains the choice of the manual for the intermediate level. because the focus of this manual shifts from grammar towards vocabulary. Students hardly join work in the classroom without clear explanation of grammar.

Despite the preparation for passing a standardized state exam (SSE), the language level is low. The results of the placement test proved it. The SSE level means to know the subject on levels from A1 to B2. In practice, few, if any, has B2 level. It is especially the case in a focus group. Another weak point of this program is its orientation. Students major in Pedagogy, Speciality "Foreign Language," which provides that future specialists must be able to communicate in English in their professional environment. However, the textbook is of general social focus. Before the research, participants filled in the placement questionnaire and completed the test to identify the English level. The test originated from a free source, an official website Macmillian (Sorokovykh, Shumeyko \& Vishnevskaya, 2020). The maximum points for the test are 60. Gradation of levels is as follows: 1-15 (Elementary), 16-30 (Intermediate), 31-45 (Upper Intermediate), 46-60 (Advanced). Twenty-four people of the group passed the test on Elementary / Pre-Intermediate level, thirteen people - on Intermediate level, and three people from the group had Upper-Intermediate level.

After establishing the current level of communicative, lexical, grammatical competencies of first-year students majoring in Pedagogy, Specialization "Foreign Language", the students identified the level of their interest in the use of social networks in foreign language classes. Therefore, we consider a survey to be a critical method of our research. The obtained data testified to the significant interest of students in learning a foreign language using new social networks. The development of a fragment of the algorithm for the use of Instagram in the study of English by first-year students majoring in Pedagogy, Specialization "Foreign Language" was followed by an input survey. To reach the goal, students filled in a questionnaire during the diagnostic, summative and final stages of the experiment. The research begins with a diagnostic test to identify the level of students' and teachers' interest in the application of social networks' potential to activate the process of acquirement of professional terminology by future specialists. It enabled identifying the urgent need for the application of modern social networks in English language learning by students. 


\section{Results}

While modelling the innovative foreign language teaching process with the implementation of publicly available social networks, it is necessary to assess the convenience of their usage from the technical point of view and the usefulness of social networks application from the learning perspective (Robelia, Greenhow \& Burton, 2011). We should note that this study presents only a few results of the survey of students and foreign language teachers. The students completed the questionnaire before they worked with social networks within mixed education. The presented part of the questionnaire had both open and closed questions, and aimed at identifying the subjective experience of students and teachers in the application of social networks, students' and teachers' thoughts and expectations from the integration of social networks into educational practice (Sorokovykh, Shumeyko \& Vishnevskaya, 2020).

Let us start with the results of the survey of the second, the third, and the fourthyear of all forms of attendance (full-time, full and part-time, and students of the correspondence department. They major in Pedagogy, Speciality "Foreign Language" (foreign language level is from B1 to C1). The first question aimed to identify the most popular social networks among students, which they use frequently. The results showed that all students had pages in several social networks; a leader is Instagram. All respondents use this network. Facebook ranks second, and Twitter ranks third (Tables 1,2).

Table 1: Students' responses the purposes of using social networks

\begin{tabular}{|c|l|}
\hline Values in $\%$ & The purpose of using social networks \\
\hline $50 \%$ & Communication with friends \\
\hline $30 \%$ & For entertainment \\
\hline $16 \%$ & For studying \\
\hline $4 \%$ & Other options for social network usage \\
\hline
\end{tabular}

Table 2: Students' responses about the total time spent on social networks

\begin{tabular}{|c|l|}
\hline Values in \% & Total time spent on social networks \\
\hline $30 \%$ & Check their pages on social networks from time to time \\
\hline $32 \%$ & I spend less than an hour a day on social networks \\
\hline $20 \%$ & More than an hour a day \\
\hline $18 \%$ & I spend all day on social networks \\
\hline
\end{tabular}

The results obtained from these questions demonstrate the high level of social network popularity among students. At the same time, they show that students lack understanding of the potential of education. In its turn, it proves the idea (Depew, 2011) that even if modern students are "digital aborigines," they often have no idea of how they can use ICT for studying. The majority of students who took part in the survey were "for" (89.8 \%), and only $10.2 \%$ were "against" when answering the question on the possibility to use social networks in the study of foreign language (Figure 2). 


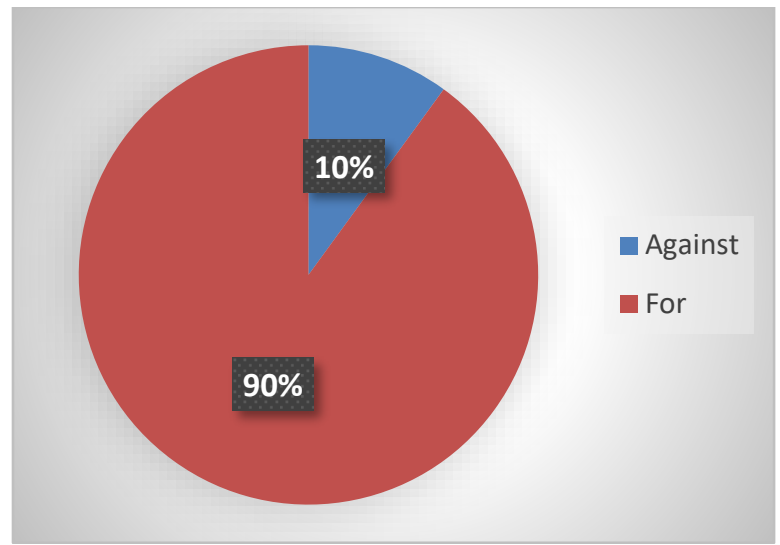

Figure 2: Application of social networks in the study of foreign language by students

The results demonstrate students' readiness and willingness to include social networks in teaching practice (audition 7). When analysing students' responses about the effectiveness of the use of social networks for the development of speech activities, we found several facts shown in Table 3.

Table 3: Effectiveness of social networks for the development of speech activities

\begin{tabular}{|c|l|}
\hline $\begin{array}{c}\text { Values in } \\
\%\end{array}$ & $\begin{array}{l}\text { Reasonability of using social networks for the development of } \\
\text { communicative foreign language knowledge, skills, abilities }\end{array}$ \\
\hline $35 \%$ & the most effective use of social networks for the development of reading \\
\hline $32 \%$ & letters \\
\hline $18 \%$ & speaking \\
\hline $15 \%$ & listening \\
\hline
\end{tabular}

All students mentioned several answers to this question (Figure 3). Thus, the research conducted among students shows popularity of social networks. The survey demonstrated that the majority of students support the idea of integrating social networks into teaching foreign language. They consider social networks as the most effective tools for learning reading and writing.

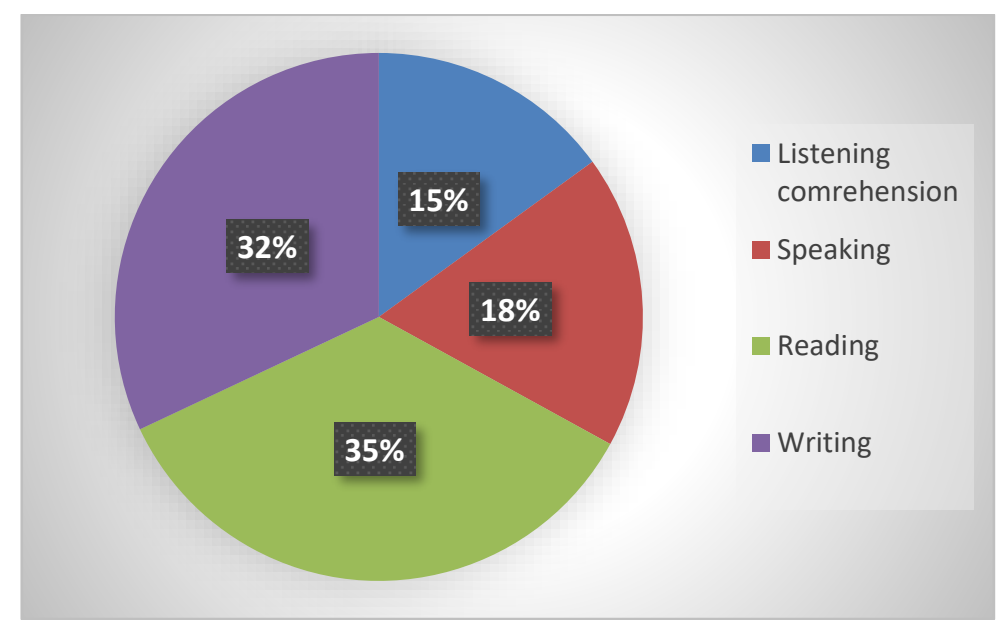

Figure 3: Assessment of the effectiveness of social networks for speech activities 
The next step was to conduct a questionnaire among teachers (Table 4). The majority of teachers-respondents are using social networks $(84.4 \%) ; 15.6 \%$ do not use social networks. The most popular social networks among teachers are Instagram (62\%, ranks first), Facebook (27\%, ranks second), and Twitter $(7 \%)$. Four percent of teachers indicated that they use different social networks.

Table 4: Time spent working on social networks by teachers

\begin{tabular}{|c|l|}
\hline Values in $\%$ & Total time spent on social networks \\
\hline $40 \%$ & Spend less than an hour a day checking their social media pages \\
\hline $50 \%$ & Check their pages on social networks from time to time \\
\hline $6,8 \%$ & Spend more than an hour a day on social networks \\
\hline $3.2 \%$ & do not use social networks \\
\hline
\end{tabular}

Majority of teachers use social networks to relax (43.8\%), to communicate with students $(34.4 \%)$, to study (18.6\%), 3.2\% chose the answer "other" (in this case in comments teachers wrote that they used social networks for communication with colleagues). 93.6 percent of teachers who took part in the survey expressed their support of social networks application in the practice of foreign language teaching. 6.4 percent of teachers demonstrated their negative attitudes (Figure 4).

Determining types of speech activities for which social networks application would be the most effective, teachers emphasized the highest level of effectiveness: for writing skills development (37\%); for reading (35\%); for listening comprehension (audition) and speaking (14\% for each) (Figure 5). Let us state that while answering this question, teachers chose several answers, rating them according to the effectiveness of using listed speech activities in social networks.

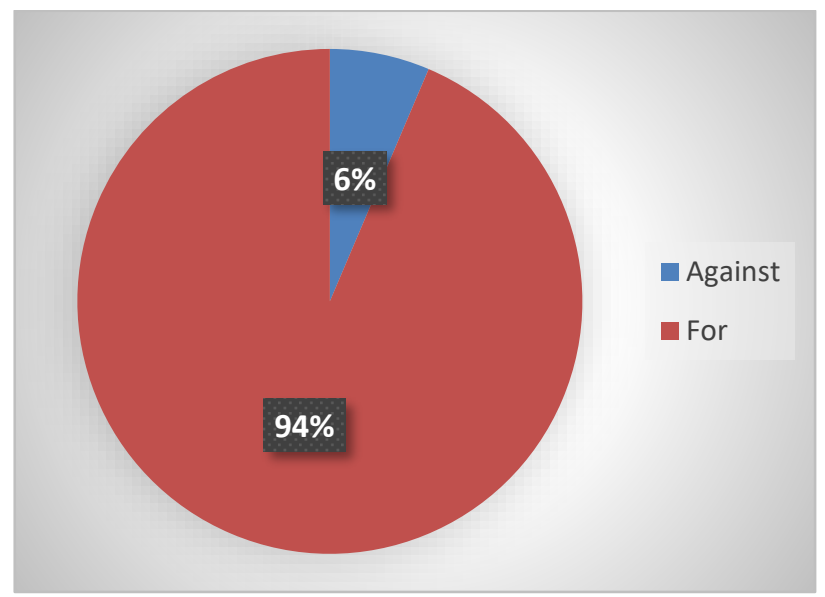

Figure 4: Teachers' opinion on social networks in foreign language teaching 


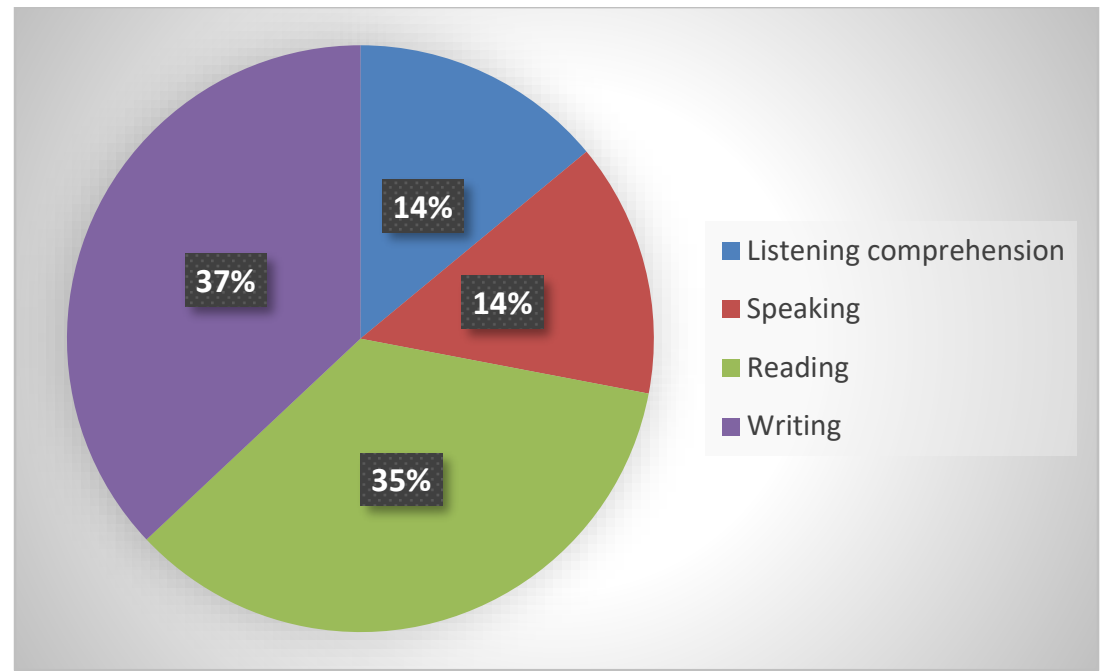

Figure 5: Appropriateness of social networks application to develop different types of speech activities (teachers' experience)

Ranking writing and reading first according to the effective development in social networks is explained by the fact that communication in social networks is mainly written, making them a convenient type for the development of such skills. Based on the comments provided by teachers, we conclude that social networks are educational space, which along with possibilities for foreign language learning offers options for tackling several educational objectives:

1. Manage the educational process. Social networks are practical means that help teachers and students communicate seamlessly. The information on cancellation, postponement of classes, holding conferences, etc. can be posted there (Arndt, 2017).

2. Individualise the educational process. Social networks allow students to complete assignments anywhere anytime; teachers can learn more about students' interests and hobbies in social networks and then use this information while planning the educational process (Ballance, 2012).

3. Organise the educational process. Teachers can continue discussions started during the lesson and post assignments for students (Gerhart, 2017).

4. Engage students who are inactive or less active during lessons in discussions (Chartrand, 2012).

5. Update students' motives for acquirement of professional terminology in the process of learning English. Social networks can be a platform for projects' preparation and delivery, organization of quizzes and competitions, conducting various surveys (Aksenova, 2015).

In general, summing up the results of students' and teachers' questionnaires leads to the following conclusion: the majority of students and teachers are registered in social networks what enables to avoid difficulties related to adaptation and exploration of a new interface, which can appear during the work with specialized educational programs. The conclusions drawn by modern researchers prove this. They stated that application of social networks reduces the number of challenges related to adaptation to a new communicative environment that can emerge in the process of working with unique educational platforms (Chartrand, 2012; Ryan, Magro \& Sharp, 2011; Shahrokni, 2009). 


\section{Discussion}

Nowadays, as the educational system is changing, it is necessary to develop new educational technologies using new resources. We tried to develop additional technique to teach students majoring in Pedagogy, Specialty "Foreign Language", the English language by applying Instagram. According to its principles, Instagram is a supplement to the main in-class practical lessons to use the English language in an authentic environment for the development of students' foreign language communicative competence (Aksenova, 2015). Data on the placement questionnaire demonstrate that all respondents $(100 \%)$ use the Internet every day. 66.7 percent use the Internet for communication and 33\% - for work and studying. Thus, $66.7 \%$ of responses proved the Internet usage in $50-80 \%$ of cases related to the need to find additional information. 16.7 percent voted for less than $50 \%$, and $16.7 \%$ voted for more than $80 \%$. The open question about the time spent on the Internet per day does not have an absolute consensus. Answers varied from 1 to 7 hours a day on average. The responses on titles of the most popular social networks ranked in a rather exciting way.

$50 \%$ of users use Instagram, $33.3 \%$ of respondents use Facebook, and $16.7 \%$ use Telegram. All respondents expressed their willingness to increase their competency level in a foreign language. $66.7 \%$ of voters are ready to do it through the Internet, and $33.3 \%$ are "rather interested." There are no leaders as regards the time that respondents are ready to spend on language learning on the Internet. $33.3 \%$ are ready to spend between $30-40$ minutes, another $33.3 \%$ are ready to spend between $40-60$ minutes, and the remaining $33.3 \%$ are ready to spend more than 60 minutes a day to study the English language on the Internet. Half of the respondents opined that it is possible to study a language through Instagram. These opinions were divided between "likely," "likely not," and "not."

These data allowed hypothesizing that the experiment would be successful because the majority of participants used the Internet every day. Besides, they use Instagram and are positive about language learning through this social network. Instagram ranks first regarding attendance of the first-year students majoring in Pedagogy, Specialty "Foreign Language." Initially, this service was for prompt photo exchange. To organise distance electronic learning of a foreign language, we recommend creating a separate account to subscribe all students of the group. Subscribers can regularly check for updates and participate in various forms of work suggested by the teacher. For students' supervised independent work and distance learning not to be spontaneous, the teacher must develop a schedule for posting publications or broadcasting live in advance. It is also useful to agree on a suitable time for live sessions with students.

The primary forms of activities for learning English on Instagram are:

- commenting on photos and pictures (as comments - the written language; as videos - an answer, and as messages - oral communication);

- posting videos with a verbal message on the topic;

- posting videos in Ukrainian/English as materials for translation;

- live sessions preparation on behalf of the teacher or with an invited student;

- short tasks and messages (photos and videos) in stories. 
So, the first form of the work is teaching through pictures and photos. A teacher posts an image on the topic of the lesson and gives assignments to comment on it. Thus, in the account specially created for this purpose, the teacher posted images on the topic "Feelings" that refer to the problem "Stay Fit and Healthy." Students had to comment on the images offered. We should note that in such terms, students themselves suggested an activity directed towards the speed and correctness of the answer. While completing this task, students will reread previous comments. It will help memorise vocabulary on the topic. The program update of 2016 enables to post not only publications that are stored in a feed, but also so-called "stories" - short 15-seconds video records limited in their number. However, each story is available only for 24 hours for subscribers. Teachers can use "stories'" as assignments for the next lesson, raise some problematic issues, draw students' attention to changes in the schedule. "Stories" is an excellent opportunity to remind subscribers about upcoming events and tests. We used "stories" to test students (Figure 6).

The third form of distance learning is the work with videos. The length of the video-content loading is 60 seconds. Video materials can be used both to introduce additional information on the topic under study and as material for translation. Videos can also be a popular "Challenge" - a problematic task posted on students' pages with an appropriate hashtag.

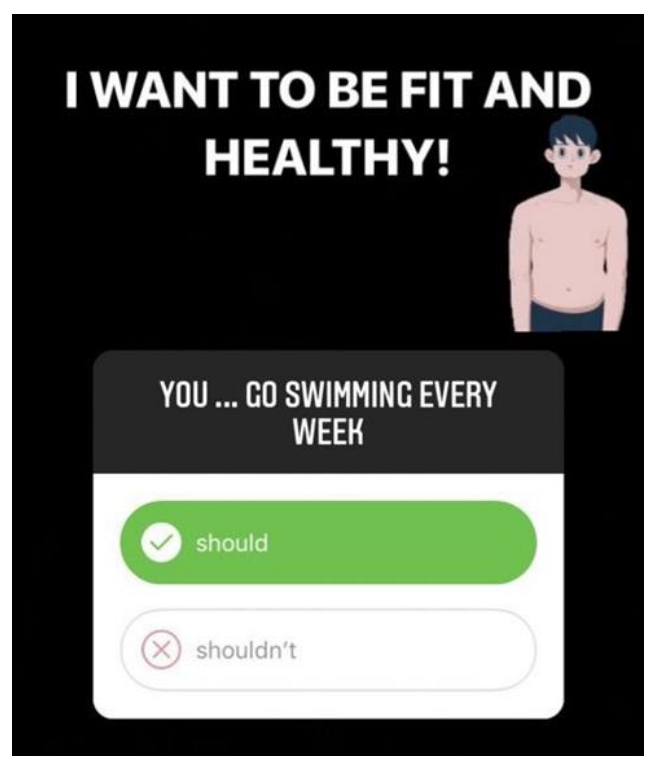

Figure 6: The application of test function in Instagram to work on grammar material (modal verb "should")

Through live sessions on Instagram, a person can study the English language. For example, it can be a session on any topics developed for independent study or supervised independent work. During a live session, it is convenient to introduce additional literature to students, and to recommend how to assimilate a particular topic. The students will have an additional stimulus not to miss a live session because it is in available up to a day (or you can set even shorter time). It is especially relevant if students are going to have a test based on this material. Moreover, a live session is appropriate for student's answers before a credit or an 
exam, a thematic colloquium or a test. Besides, a live session provides an opportunity to work on the main mistakes made in tests, to provide examples of communicative situations that will be presented on exams.

Thirdly, the possibility to invite a speaker for a live session enables teachers to engage students in active participation. The organization of this type of project work should be as follows: the teacher develops a schedule of distance sessions, according to which each student prepares a particular topic. On the appointed day and time, a teacher goes live and invites a student to join. Other subscribers join the session, listen to reports, and ask questions. The teacher assesses both the readiness of the student who organizes the session and the level of activity of other students. The teacher can also ask questions or add some information. It is especially important in the first stages of this type of work, when the activity of participants is low. While teaching the topic "Travel", the teacher suggested watching a video about Singapore, a city of the future, demonstrated on National Geographic. Regarding grammar, the teacher repeated information about modal verbs.

In general, an obligatory part of such an experiment lasts four weeks. However, there were some breaks between weeks during which the group's activity did not stop. The teacher posted games, songs, and funny materials. The students, having understood it, also shared their stories. After the end of the testing, students filled in a final questionnaire, and passed a test to identify the language level one more time. The majority of students admitted that many questions became clearer after the course completion. Thus, nine participants succeeded in improving their first results. Thirty people proved their level, and one student passed the test worse than the first one.

The final questionnaire showed the following statistics. The participants used Instagram every day. $66.7 \%$ of respondents revealed that they spent $15-20$ minutes a day to become familiar with the group's material, $16.7 \%$ spent between $5-10$ minutes, and another $16.7 \%$ spent more than 60 minutes. $66.7 \%$ spent $20-30$ minutes on social interaction, and $33.3 \%$ spent only $15-20$ minutes. $50 \%$ of respondents used dictionaries while writing their posts, $33.3 \%$ did it quite often, and only $16.7 \%$ did it rarely. All respondents answered used their smartphones to search for relevant resources. Following the results of the experiment, the participants assessed Instagram as a way to obtain new knowledge of the foreign language. $83.3 \%$ gave a favourable consideration to this method, and $16.7 \%$ gave a negative one. Thus, the research received positive feedback from students, even though students did not actively engage in the core activities.

The results confirm the existing conclusions of researchers that the academic potential and features of the use of virtual social networks are due to their accessibility to most Internet users (Klimenko, 2012). The very ideology and interface of Instagram make it possible to save time when there is no need to organise the adaptation of students to a new educational tool and a communicative space. Virtual social networks also contribute both to formal and informal communication between teachers and students, making it possible to 
implement the technology of personality-oriented learning. We agree with the position of modern scholars that the multimedia of the communicative space greatly facilitates uploading video and audio materials, interactive applications, and viewing them in the virtual learning space (Huang \& Hung, 2013).

In addition to the above possibilities of using virtual social networks in teaching foreign languages, including English, the combination of individual and group forms of educational work with the help of virtual networks allows us to achieve a better understanding and assimilation of educational materials, as well as the individualization of learning. The common communicative space of virtual social networks for all subjects of the foreign language learning process allows us to jointly assess both the process and the results of completing academic assignments, observe the dynamics of success of each member of the virtual learning group and track their activities.

Current modernization processes in higher education provide for shifting a significant proportion of academic time from in-class hours to independent work of students. The use of virtual social networks has a similar effect. It makes the use of research approaches in learning, independent and group search for information to solve the problem set by the teacher, to develop the ability to search for the necessary information independently, to work in a team, to perform collective search activities, and make interaction with groupmates more popular and accessible.

\section{Conclusions}

Modern technologies are incredibly popular, especially mobile devices and computers with access to the Internet. Many foreign universities use mobile devices to optimise the educational process. They are a supplement to the main educational program creating unique educational games. The popularization of social networks is ongoing. Their functions are changing and transforming from purely social to broader ones. The process of foreign language learning reflects these trends. The main goal of foreign language teaching in HEIs is the formation of the communicative skills of students. There is an urgent need to create a new way to develop students' communicative skills in the context of reducing hours provided for foreign language learning and increasing number of students in one group. Instagram was an attempt to reach these goals. The study provides a short instruction on the possible application of Instagram for educational purposes in the process of learning. The developed algorithm implies the active cooperation between students and a teacher on the Internet by using social networks to improve the communicative skills of future specialists. The technique was tested on 40 first-year students majoring in Pedagogy, Specialty "Foreign Language." During the experimental verification of the efficiency of this technique, Instagram was used as an additional resource as indicated in the program. The experiment was not extended, though it can provide practically oriented conclusions and produced positive results in the level of students' English language skills. Further research may involve a subsequent improvement of the methodology for the formation of professional culture in law students in their professional training at the undergraduate level. 


\section{References}

Aksenova, I. N. (2015). An independent work on the Internet during the process of foreign language learning by journalists obtaining a bachelor's degree and studying a discipline "Foreign language for special purpose." In O. A. Chekun (Ed.), Modern language education: innovation, problems, solutions: collection of scientific works (pp. 53-55). Moscow, Russia: M. A. Sholokhov RIC MGGU.

Arndt, H. (2017). The role of online media in 21st century language learning. Retrieved from https://connectedlife.oii.ox.ac.uk/the-role-of-online-media-in-21st-centurylanguage-learning/

Aydin, S. (2014). Foreign language learners' interactions with their teachers on Facebook. System, 42, 155-163. http://dx.doi.org/10.1016/j.system.2013.12.001

Ballance, O. J. (2012). Mobile language learning: More than just "The platform". Language Learning and Technology, 16(3), 21-23.

Bezukladnikov, K. E., Novosyolov, M. A., \& Kruze, B. A. (2014). The international teachers foreign language professional communicative competency development. Procedia - Social and Behavioral Sciences, 154, 329-332. https:// doi.org/10.1016/j.sbspro.2014.10.158

Birky, I., \& Collins, W. (2011). Facebook: maintaining ethical practice in the cyberspace age. Journal of College Student Psychotherapy, 25(3), 193-203. https://doi.org/10.1080/87568225.2011.581922

Boyd, D. M., \& Ellison, N. B. (2007). Social network sites: definition, history, and scholarship. Journal of Computer-Mediated Communication, 13(1), 210-230. https://doi.org/10.1111/j.1083-6101.2007.00393.x

Chartrand, R. (2012). Social networking for language learners: Creating meaningful output with Web 2.0 tools. Knowledge Management and E-learning: An International Journal, 4(1), 97-101.

Chen, H. I. (2013). Identity practices of multilingual writers in social networking spaces. Language Learning and Technology, 17(2), 143-170.

Dellar, H., \& Walkley, A. (2010). Outcomes Intermediate. Boston, MA: Cengage Learning.

Depew, K. E. (2011). Social media at academia's periphery: Studying multilingual developmental writers' Facebook composing strategies. Reading Matrix: An International Online Journal, 11(1), 54-75.

Gerhart, N. (2017) Technology addiction: How social network sites impact our lives. Informing Science: the International Journal of an Emerging Transdiscipline, 20, 179194. https:// doi.org/10.28945/3851

Gilpin, D. R. (2011). Working the Twittersphere: Microblogging as professional identity construction. In Z. Papacharissi (Ed.), A networked self: Identity, community, and culture on social network sites (pp. 232-250). New York, NY: Routledge.

Hall, J., \& Walsh, M. (2002). Teacher-student interaction and language learning. Annual Review of Applied Linguistics, 22(1), 186-203. https://doi.org/10.1017/S0267190502000107

Handley, A., \& Chapman, A. (2011). Content rules: How to create killer blogs, podcasts, videos, ebooks, webinars (and more) that engage customers and ignite your business. Hoboken, NJ: Wiley.

Huang, H.-T. D., \& Hung, S.-T. A. (2013). Exploring the utility of a video-based online EFL discussion forum. British Journal of Educational Technology, 44(3), 90-94. https:// doi.org/10.1111/j.1467-8535.2012.01373.x

Junco, R., \& Cole-Avent, G. A. (2008). An introduction to technologies commonly used by college students. New Directions for Student Services, 124, 3-17. https://doi.org/10.1002/ss.292 
Kabilan, M. K., Ahmad, N., \& Abidin, M. J. Z. (2010). Facebook: An online environment for learning of English in institutions of higher education. Internet and Higher Education, 13(4), 179-187. http://dx.doi.org/10.1016/j.iheduc.2010.07.003

Klimenko, O. A. (2012). Social networks as means of teaching and cooperation between participants of educational process. Proceedings of the International correspondence scientific conference: Theory and practice of education in the modern world (pp. 405-407). St-Peterburg, Russia: Renom.

Lin, C.-H., Warschauer, M., \& Blake, R. (2016). Language learning through social networks: perceptions and reality. Language Learning $\mathcal{E}$ Technology, 20(1), 124-143.

Maguth, B., Yamaguchi, M., \& Elliott, J. (2010). Researching, producing, and presenting: Use of technology for global advocacy in the social studies. Social Education, 74(2), 105-106.

Mills, N. A. (2009). Facebook and the use of social networking tools to enhance language learner motivation and engagement. Paper presented at the Northeast Association for Language Learning Technology Conference. New Haven, NY: Yale University.

Mills, N. A. (2011). Situated learning through social networking communities: The development of joint enterprise, mutual engagement, and a shared repertoire. CALICO Journal, 28(2), 345-368.

Mozhaeva, G. V., \& Feshchenko, A. V. (2010). The use of virtual social networks in the education of humanitarian students. Proceedings of the International scientific conference: Information resources, technologies and models of reconstruction of historical processes and phenomena (pp. 174-175). Moscow, Russia: MSU.

Redston, C., \& Cunnigham, G. (2012). Face2face elementary: student's book with DVD-ROM ( $2^{\text {nd }}$ ed.). Cambridge, UK: Cambridge University Press.

Reinhardt, J., \& Chen, H. (2013). An ecological analysis of social networking site-mediated identity development. In M.-N. Lamy, \& K. Zourou (Eds.), Social Networking for Language Education (pp. 11-30). Basingstoke, UK: Palgrave Macmillan.

Robelia, B. A., Greenhow, C., \& Burton, L. (2011). Environmental learning in online social networks: adopting environmentally responsible behaviors. Environmental Education Research, 17(4), 553-575. http://dx.doi.org/10.1080/13504622.2011.565118

Roblyer, M. D., McDaniel, M., Webb, M., Herman, J., \& Witty, J. V. (2010). Findings on Facebook in higher education: A comparison of college faculty and student uses and perceptions of social networking sites. Internet and Higher Education, 13(3), 134-140. https://doi.org/10.1016/j.iheduc.2010.03.002

Romano, T. (2009). Defining fun and seeking flow in English language arts. English Journal, 98(6), 30-37.

Ryan, S. H., Magro, M. J., \& Sharp, J. K. (2011). Exploring educational and cultural adaptation through social networking sites. Journal of Information Technology Education, 10(1), 1-16.

Schmitt, N. (2008). Instructed second language vocabulary learning. Language Teaching Research, 12(3), 329-363.

Shahrokni, S. (2009). Second language incidental vocabulary learning: The effect of online textual, pictorial, and textual pictorial glosses. TESL-EJ, 13(3), 1-17.

Sorokovykh, G. V., Shumeyko, T. N., \& Vishnevskaya, E. M. (2020). Innovations in teaching future engineers discussion-enlightenment culture of foreign speech. In Z. Anikina (Ed.), Proceedings of the Conference Integrating Engineering Education and Humanities for Global Intercultural Perspectives (pp. 128-137). Cham, Switzerland: Springer. https://doi.org/10.1007/978-3-030-47415-7_14

Yavuz, F. (2012). Adaptation of KWL charts to the Internet and the use of web pages in English language teaching. Haziran, 15(27), 403-411. 